\title{
MATHEMATICAL MODELING OF THE COLD ROLLING PROCESS AND HEAT TREATMENT FOR DCO1 STEEL
}

\author{
Marian-Iulian NEACȘU \\ "Dunărea de Jos" University of Galaţi, Romania \\ e-mail: uscaeni@yahoo.com
}

\begin{abstract}
The paper presents the elaboration of a mathematical model of the cold strip rolling process combined with the recrystallization annealing after the rolling at LBR Liberty Galati.

The elaborated mathematical model allows the prediction of the mechanical properties of cold rolled strips subsequently subjected to a heat treatment.

The realization of this mathematical model was based on statistical measurements of the mechanical properties $R m, R_{p 0.2}(R c)$ and $A_{5}$ for the rolled steel strip DC01 from Liberty Steel Galati. To achieve this mathematical model, the active experiment method was used.

With the help of this mathematical model, it is possible to optimize the rolling process by significant savings of time and materials in the process of testing the mechanical properties for cold rolled tape, but also by choosing the most appropriate process parameters.
\end{abstract}

KEYWORDS: mathematical model, mechanical properties, statistical measurements, active experiment, recrystallization annealing

\section{Introduction}

Process modeling is a useful basic tool both in the design phase and in the analysis of the operation of metallurgical installations. This, together with the use of computers, allows the determination of the optimal regimes of metallurgical processes. The development of the specific mathematical apparatus and of the statistical methods allowed to approach the problem of the optimal decision as a problem of great technical and economic efficiency [1].

Mathematical modeling is a basic tool in the design phase but also in the execution phase as well as in the analysis of the functioning of the processes. With the help of mathematical modeling and computers by using specialized programs, we can determine the optimal conditions for a metallurgical process [2].

The construction of models associated with processes and systems is an essential side of the simulation process, a distinction between the different types of models that can be used by analysts being absolutely necessary [3].

The modeling process can be considered as consisting of two stages:
- one that specifies the form in which the model is to be expressed.

- and the second stage is the one that describes how the mathematical model is used to provide a series of predictions or to offer the optimal solution of the studied problem. The mathematical model of a process, in this case a metallurgical process, is used to determine the best conditions for the process but can also be used to provide information on the optimal management of the process [4].

However, some very important factors should not be neglected in the evaluation of modeling methods, such as: the relative cost of using these models (their efficiency), the ease with which they can be transmitted from those who made them to those who apply them, handling facilities, the degree of accuracy offered, the limits within which the respective models can be applied.

Mathematical modeling is the transposition into a mathematical form of a real physical process.

Statistical mathematical modeling is performed in two stages:

- in the first stage, which is called a preliminary experiment, the problem of choosing the process factors as well as the interactions that may occur are solved; 
- in the second stage, the experiment on which the operator relies to perform the actual modeling and statistical analysis of the model takes place [5].

Operational research, like other research disciplines, has progressed through the use of mathematical models, which concisely use mathematical notations to represent the variable states in the system and to describe how variables change and interact with each other. Predictions regarding the behavior of the system are made with the help of symbolic representations, through mathematical procedures.

\section{Experimental conditions}

In the paper we realized the mathematical model of the process of cold plastic deformation and heat treatment of recrystallization annealing applied to the studied alloy by statistical methods, namely regression analysis by active experiment.

A number of 25 experiments were performed in a cold rolled strip trial, the brand of the material being DC01, on which degrees of reduction between 61 and $65 \%$ were applied with a step of $1 \%$, and in the thermal treatment of recrystallization annealing, times were maintained at $700{ }^{\circ} \mathrm{C}$ between 35 and 39 hours as well as a 1-hour step.

The following technological parameters were taken into account as main influencing factors (independent variables) of the process:

- recrystallization annealing heat treatment time $-\tau$, [hours];

- degree of plastic deformation - $\varepsilon$, [\%].

To establish the baseline and the range of variation of the influencing factors we used values obtained from mechanical tests on the samples used.

Thus, we established the following experimental conditions:

- for the duration of recrystallization annealing heat treatment:

- basic level: $X_{01}=37$ hours;

- variation interval: $\Delta X_{1}=2$ hours;

- upper level: $X_{1 \mathrm{~s}}=39$ hours;

- lower level: $X_{1 \mathrm{i}}=35$ hours.

- for the degree of deformation:

- basic level: $\mathrm{X}_{02}=63 \%$;

- variation range: $\Delta \mathrm{x}_{2}=2 \%$;

- upper level: $\mathrm{X}_{2 \mathrm{~s}}=65 \%$;

- lower level: $\mathrm{X}_{2 \mathrm{i}}=61 \%$.
In order to represent the coded experiment, the following notations and symbols were used:

Independent variables:

- $X_{1}$ - recrystallization annealing heat treatment time, $\tau$ [hours];

- $\mathrm{X}_{2}$ - degree of deformation, $\varepsilon[\%]$;

Dependent variables (parameters to be optimized):

- $\mathrm{Y}_{1}$ - breaking strength, Rm [MPa];

- $\mathrm{Y}_{2}$ - flow limit, $\mathrm{R}_{\mathrm{p} 0.2}[\mathrm{MPa}]$;

- $\mathrm{Y}_{3}$ - specific elongation at break, $\mathrm{A}_{5}[\%]$;

There are the following links between natural and coded values of factors $\mathrm{x}_{\mathrm{i}}$ :

$$
x_{1}=\frac{\tau-\tau_{0}}{\Delta \tau}, x_{2}=\frac{\varepsilon-\varepsilon_{0}}{\Delta \varepsilon}
$$

Yi values are expressed in natural units.

Next, based on the matrix of the complete factorial experiment, the coefficients of the regression equation are calculated (mathematical model). Considering the $\mathrm{Yi}$ function as the analytical expression of the first order model, it is of the form:

$$
Y_{i}=c_{0}+\sum_{i=1}^{2} c_{i} \cdot x_{i}+\sum_{\substack{i=1 \\ j=1 \\ i \neq j}}^{2} c_{i j} x_{i} x_{j}
$$

Following the specific calculations, the equations of the mathematical model (3), (4), (5) resulted for the three studied mechanical properties:

$$
\begin{gathered}
Y_{1}(\tau, \varepsilon)=859,25-6 \cdot \tau-5,25 \cdot \varepsilon \\
Y_{2}(\tau, \varepsilon)=1004,19-11,31 \cdot \tau-8,44 \cdot \varepsilon+0,06 \cdot \tau \cdot \varepsilon \\
Y_{3}(\tau, \varepsilon)=-163,25+2,5 \cdot \tau+1,75 \cdot \varepsilon
\end{gathered}
$$

\section{Experimental results}

Following the laboratory tests on the specimens taken from the rolls caught in the experimental program, the values of the studied mechanical properties were registered. The variation of these values depending on the two parameters of the process are illustrated in Figures 1, 2, 3. 

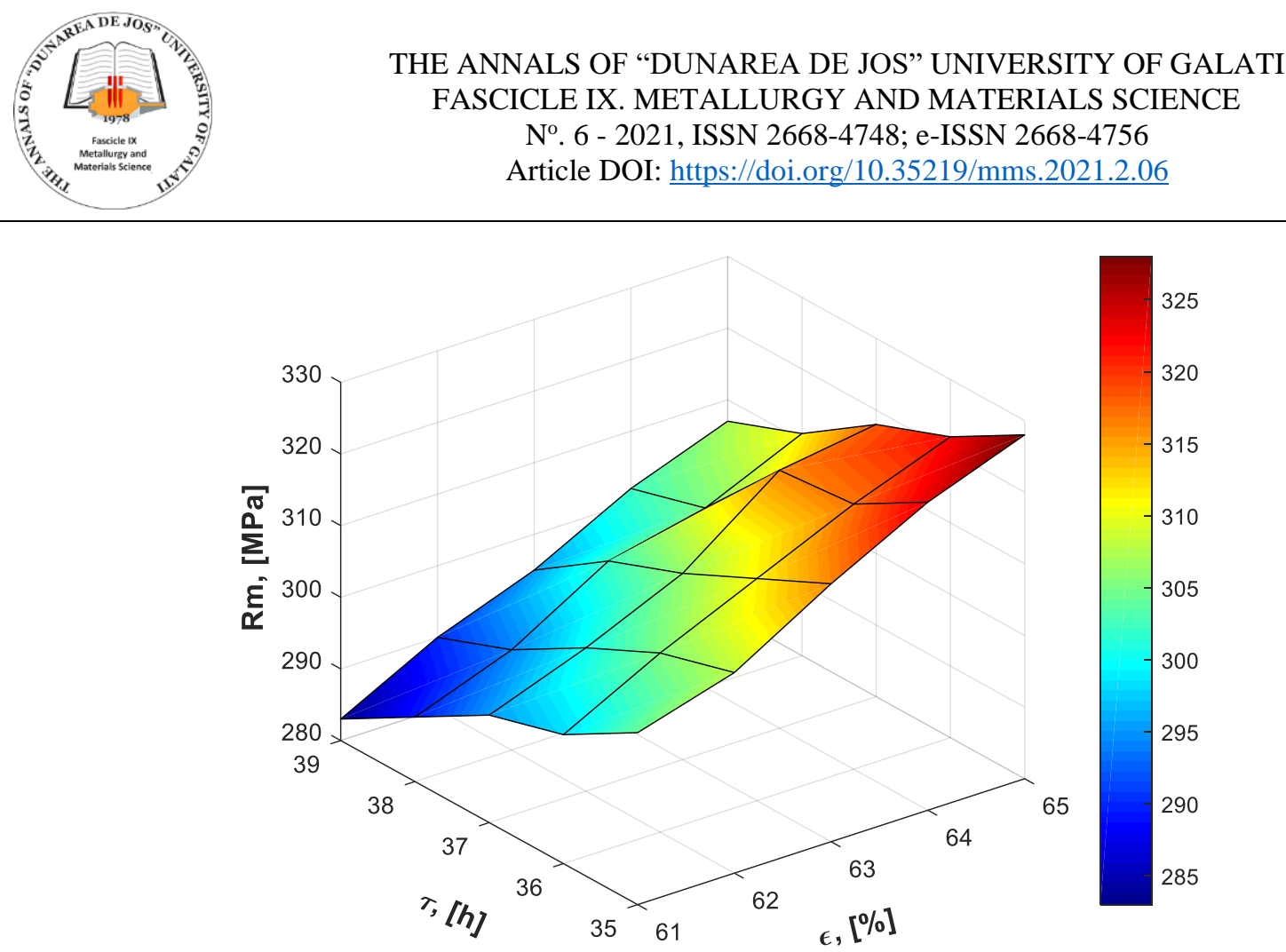

Fig. 1. Variation of mechanical strength with the degree of cold plastic deformation and with the time of recrystallization annealing

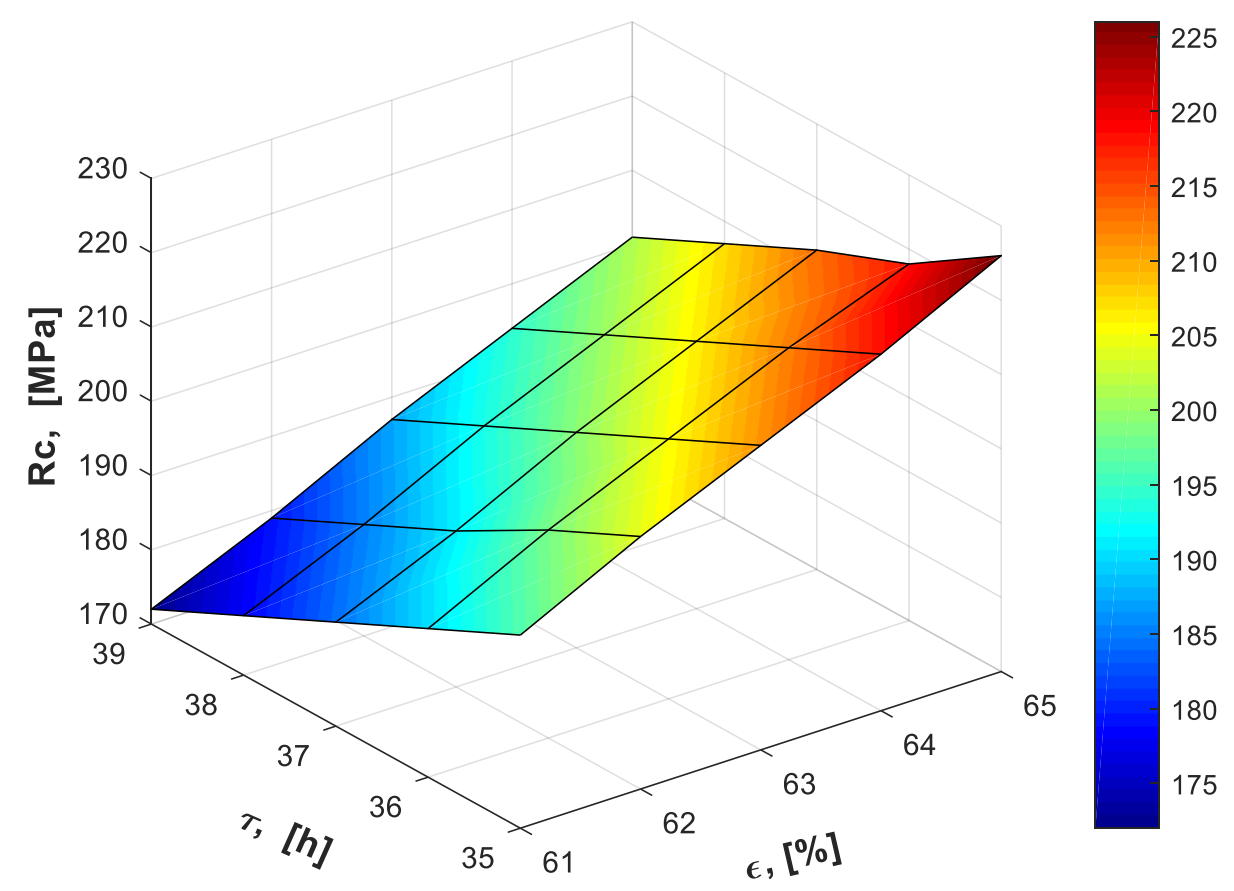

Fig. 2. Variation of the flow limit with the degree of cold plastic deformation and with the recrystallization annealing time 


\section{THE ANNALS OF “DUNAREA DE JOS” UNIVERSITY OF GALATI \\ FASCICLE IX. METALLURGY AND MATERIALS SCIENCE \\ No $^{\circ} 6$ - 2021, ISSN 2668-4748; e-ISSN 2668-4756 \\ Article DOI: https://doi.org/10.35219/mms.2021.2.06}

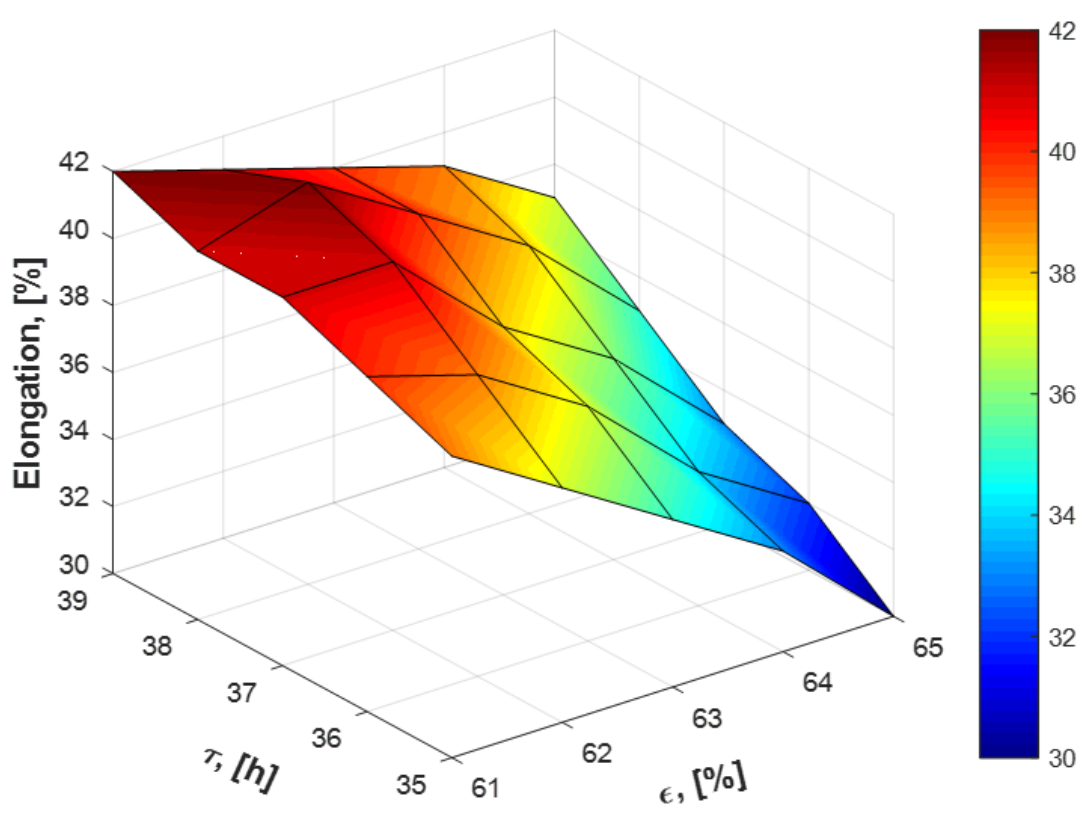

Fig. 3. Variation of elongation at break with the degree of cold plastic deformation and with the time of recrystallization annealing

\section{Conclusions}

During this research work, several technological variants for obtaining cold rolled steel strips of DC01 brand were studied, in the conditions of Liberty Steel Galati.

For all the 25 technological variants studied, the related mechanical properties comply with the norms in force on the Liberty Steel Galati platform (SR EN 10310).

Carrying out the mathematical modeling of the process of obtaining cold-rolled strips led to obtaining mathematical equations of the studied process, valid for a time $\tau$, with values ranging from 35 hours to 39 hours, maintenance to recrystallization annealing and a degree deformation during cold rolling $\varepsilon$, with values between $61-65 \%$.

The equations of the mathematical model obtained are first order equations and were statistically verified using the Fischer criterion.

The mathematical model obtained in this paper can be likened to a function with two variables, each of the three studied mechanical properties (output quantity) depends on: $\tau$ [hours];

- recrystallization annealing heat treatment time,

- degree of deformation, $\varepsilon[\%]$;

In the future, for the three studied mechanical properties, the equations of the mathematical model allow the prediction of the values of these properties by calculation, without the need to perform specific mechanical tests.
Interpreting the equations of the model, it results that the mechanical properties of resistance increase as the value of the degree of deformation increases and decrease as the recrystallization annealing time decreases.

Elongation at break is influenced, according to the mathematical model, primarily by the treatment time in the sense that, as the temperature of the recrystallization annealing heat treatment increases, so does the elongation.

The presented mathematical model allows the calculation of the optimization of the parameters of the process of obtaining cold rolled strips in Liberty Steel Galati, so as to obtain the optimal complex of resistance and plasticity properties, with minimal costs.

\section{References}

[1]. Taloi D., Bratu C., Florian E., Berceanu E., Optimizarea proceselor metalurgice, E.D.P., Bucureşti, 1983.

[2]. Taloi D., Optimizarea proceselor tehnologice-aplicaţii în metalurgie, Editura Academiei, Bucureşti, 1987.

[3]. Popescu D., Ionescu F., Dobrescu R., Stefanoiu D., Modelare in ingineria proceselor industriale, Editura AGIR Bucuresti, 2011.

[4]. Ciuca I., Dumitriu S., Modelarea si Optimizarea proceselor metalurgice de deformare plastica si tratamente termice, Ed. Didactica si Pedagogica, Bucuresti, 1998.

[5]. Baron T., et al., Statistică teoretică şi economică, Editura Didactică şi Pedagogică, Bucureşti, 1995.

[6]. Cazimirovici E., Bazele teoretice ale deformării plastice, Ed. Bren Bucureşti, 1999. 